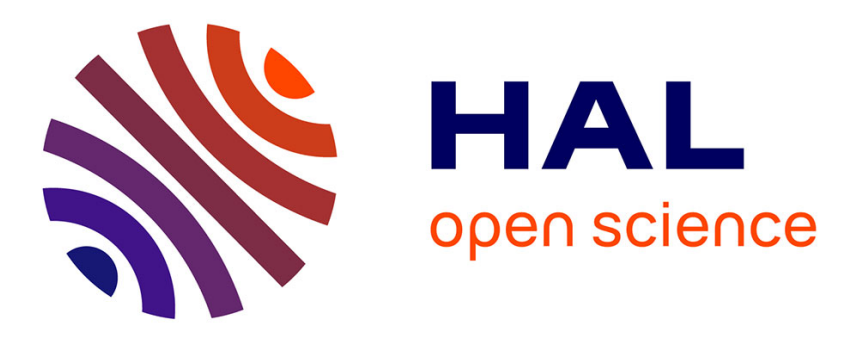

\title{
The study of interfacial phenomena using impedance measurements in conjunction with complementary techniques
}

\author{
M. Sluyters-Rehbach, J. Sluyters
}

\section{- To cite this version:}

M. Sluyters-Rehbach, J. Sluyters. The study of interfacial phenomena using impedance measurements in conjunction with complementary techniques. Journal de Physique IV Proceedings, 1994, 04 (C1), pp.C1-95-C1-105. 10.1051/jp4:1994106 . jpa-00252448

HAL Id: jpa-00252448

https://hal.science/jpa-00252448

Submitted on 1 Jan 1994

HAL is a multi-disciplinary open access archive for the deposit and dissemination of scientific research documents, whether they are published or not. The documents may come from teaching and research institutions in France or abroad, or from public or private research centers.
L'archive ouverte pluridisciplinaire HAL, est destinée au dépôt et à la diffusion de documents scientifiques de niveau recherche, publiés ou non, émanant des établissements d'enseignement et de recherche français ou étrangers, des laboratoires publics ou privés. 


\title{
The study of interfacial phenomena using impedance measurements in conjunction with complementary techniques
}

\section{SLUYTERS-REHBACH and J.H. SLUYTERS}

Electrochemistry Department, Utrecht University, Paduallaan 8, P.O. Box 80.051, 3508 TB Utrecht, The Netherlands

\begin{abstract}
It is explained why and how in particular cases additional information from complementary methods should be used to validate and to improve the information obtained from impedance measurements.
\end{abstract}

As an example we present the direct determination of charge density vs potential curves with a newly developed dropping mercury micro electrode, and its application to prove the specific adsorption of the alkali ions at the mercury / aqueous solution interface.

As a second example the study of electrode reactions with a finite rate of charge transfer and complicated by adsorption of the reactant is discussed. Here the combination of impedance measurements with high frequency demodulation measurements is indispensable. This is illustrated by some results for the system (TI (I) / $\mathrm{Tl}(\mathrm{Hg})$ in $1 \mathrm{M} \mathrm{HCI} \mathrm{O}_{4}$.

\section{INTRODUCTION}

Interfacial electrochemistry is the field that comprises the study of phenomena primarily involved in electrode processes such as charge transfer, adsorption/desorption, electrocatalysis, double layer charging, etc. Almost always these processes are accompanied by secondary events like mass transfer to and from the interface, and bulk conduction of electricity.

One of the most powerful methods to study these partial processes, their contribution to the whole, and the effects of system conditions upon them, is the impedance technique. Some of the reasons are:

- $\quad$ its high precision, and ability of noise rejection

- $\quad$ its large frequency range (i.e. time scale) covered, enabling to unravel slow and fast processes

- the possibility to measure ac data as a function of the potential in a very wide range, which favours the elucidation of reaction mechanisms

- the resolution of the data into a real and imaginary component, which facilitates data analysis

- the relative simplicity of the mathematics, due to their formulation in the frequency domain instead of the time domain. 
The advanced development of these mathematical descriptions is partly due to many experimental studies at the (almost) "ideal" interface: mercury / aqueous solution [1-3], and also to so-called unified formalisms $[4,5]$. Later it became recognized that impedance data not always provide the unambiguous information that would be desired. For example:

- different equivalent circuits may obey the same frequency dependence [6]

- $\quad$ surface inhomogeneity seriously complicates the frequency dependence $[7,8]$

- distinction between first order and more complex reaction mechanisms is (mostly) theoretically impossible [5, 9].

In many of such cases it is useful, and even necessary to investigate the system by combining results of perturbation methods that are typically of different order [10]. For the impedance method (first order) this means that it may be combined with de voltammetry or chronoamperometry (zeroth order) and/or with second harmonic ac volammetry or demodulation voltammetry (second order)

In this paper we want to give a brief overview of two recent studies in our laboratory, where this principle of complementary methods appeared essential:

(i) adsorption of neutral and ionic species in the electrical double layer

(ii) charge transfer kinetics of reactions complicated by reactant adsorption.

\section{DOUBLE LAYER ANALYSIS}

We consider a solution containing an electrolyte and a neutral species $\mathrm{A}$, in contact with a metallic electrode. The determination of the surface excesses $\Gamma_{i}$ of the solutes, adsorbed or desorbed at the interface, relies on thermodynamic relationships. For example the change of the interfacial tension $\gamma$ with the thermodynamic potential $\mu$ at constant electrode potential, $E$ [11]:

$$
-\left(\frac{\partial \gamma}{\partial \gamma_{\mathrm{A}}}\right)_{\mu_{\mathrm{salt}, \mathrm{E}}}=\Gamma_{\mathrm{A}} \quad, \quad-\left(\frac{\partial \gamma}{\partial \mu_{\mathrm{salt}}}\right)_{\mu_{\mathrm{A}, \mathrm{E}-}}=\Gamma_{+}
$$

where $\mathrm{E}$ is the potential referred to an external reference electrode, and $\mathrm{E}$ the potential to an internal reference electrode reversible to the anion of the electrolyte. An alternative route, preferable because of its higher sensitivity, is the change in electrode potential with the thermodynamic potential at constant charge density, $\sigma^{\mathrm{M}}$ :

$$
\begin{aligned}
& -\left(\frac{\partial \mathrm{E}}{\partial \mu_{\mathrm{A}}}\right)_{\mu_{\text {salt, } \sigma^{M}}}=\left(\frac{\partial \Gamma_{\mathrm{A}}}{\partial \sigma^{\mathrm{M}}}\right)_{\mu_{\text {salt }, E}} \\
& -\left(\frac{\partial \mathrm{E}_{-}}{\partial \mu_{\text {salt }}}\right)_{\mu_{\mathrm{A}, \sigma^{M}}}=\left(\frac{\partial \Gamma_{+}}{\partial \sigma^{\mathrm{M}}}\right)_{\mu_{\mathrm{A}, \mathrm{E}_{-}}}
\end{aligned}
$$

Integration of the experimental values of $\left(\partial \mathrm{E} / \partial \mu_{\mathrm{i}}\right)$ with respect to $\sigma^{\mathrm{M}}$ gives $\Gamma_{\mathrm{i}}$. Therefore it is needed to measure $\sigma^{\mathrm{M}}$ vs $\mathrm{E}$ (or $\mathrm{E}_{-}$) at varied activity of the solute. 


\section{DOUBLELAYER PARAMETERS}

Mostly the primary experimental parameter is the double layer capacitance $C_{d}$, derived from impedance measurements. The charge density is then obtained by integrating

$$
\int_{E_{p z c}}^{E} C_{d} d E=\sigma^{M}(E)
$$

At solid electrodes $\mathrm{C}_{\mathrm{d}}$ is by far the only directly accessible parameter, though academically speaking oM could also be determined by integrating the current following a potential step perturbation, e.g. from the zero charge potential $E_{\text {pzc }}$ to $E$. At mercury $\sigma^{\mathrm{M}}$ is also directly accessible as the integral of the charging current flowing when a mercury drop is extruded from the capillary of a dropping mercury electrode (DME) [12].

Fig. 1a represents $C_{d}$ vs $E$ curves at a DME for the adsorbate $t$-butanol at several concentrations. It shows the typical adsorption-desorption peaks at potentials remote from the pzc, suggesting that the surface excess is zero at potentials beyond those peaks. This means, according to eqn (2a), that the $\sigma^{\mathrm{M}}$ vs $E$ curves should coincide at extreme posive and negative charge densities. However, in Fig. 1b it is seen that the integrated capacitance data fail to do so.
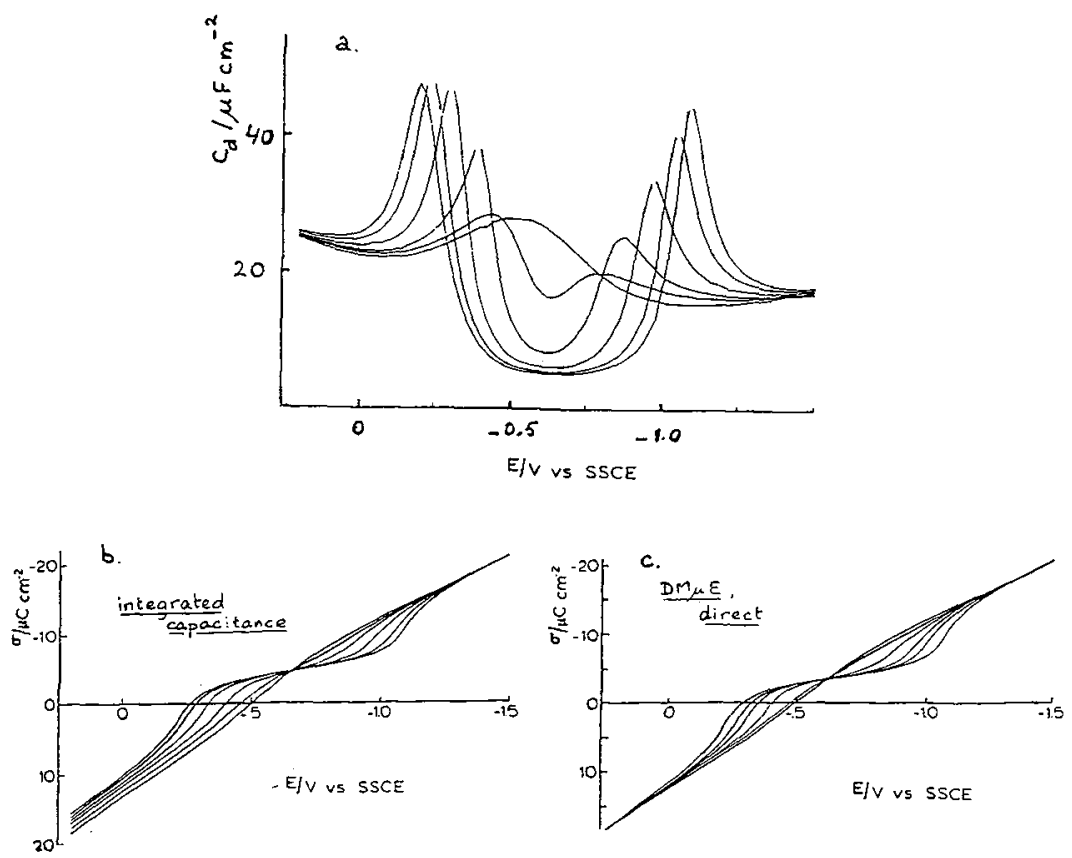

Fig. 1. a) capacitance vs potential at the DME for solutions of $1 \mathrm{M} \mathrm{NaClO}_{4}$ and $\mathrm{t}$-butanol $(0,0.06,0.10,0.18,0.30$, $0.40 \mathrm{M}$ )

b) corresponding o ${ }^{M} v$ s $E$ curves, obtained by integration of a) from $E=-1.5 \mathrm{~V}$ vs SSCE

c) corresponding $\sigma^{\mathrm{M}}$ vs $\mathrm{E}$ curves, directly measured with a DM $\mathrm{DE}$. 
Similar discrepancies are often mentioned in the literature $[13,14]$, but mostly without a statisfactory explanation. Briefly it should be as follows.

(i) Impedance measurements are non-thermodynamic by definition. Therefore, at low concentrations the adsorption process is controlled by diffusion, and correspondingly the interfacial admittance $Y$ depends on the frequency according to [3]

$$
\begin{aligned}
& Y=\omega C_{a} \frac{u+i(u+2)}{u^{2}+2 u+2}+i \omega C_{H F} \\
& C_{a}=\left(\partial \sigma^{M} / \partial \Gamma_{A}\right)_{E}\left(\partial \Gamma_{A} / \partial E\right)_{c_{A}} \\
& u=u^{\prime} \omega^{1 / 2}=\left(\partial \Gamma_{A} / \partial c_{A}\right)_{E}\left(2 \omega / D_{A}\right)^{1 / 2} \\
& C_{H F}=\left(\partial \sigma^{M} / \partial E\right)_{\Gamma_{A}}
\end{aligned}
$$

Eqn (4) shows that the usual procedure of extrapolating the "apparent double layer capacitance" (however defined) to zero frequency can not be rigorous. A three parameter fit is needed to obtain the quantity $C_{L F}=C_{A}+C_{H F}$, which is thermodynamically meaningful, and which can be integrated to obtain $\sigma^{\mathrm{M}}$.

(ii) Impedance measurements rely on the first order small amplitude current-potential relationship by definition. However, in the region of the peaks the capacitance-potential relationship is highly nonlinear and will easily produce second and third order responses. The latter contains a contribution at the fundamental frequency $\omega$ and consequently contaminates the response measured at this frequency. To our knowledge this effect has in this context not been recognized before. It would be negligible at perturbations with very small amplitudes, too small to guarantee sufficient experimental precision. In Fig. 1c the o $\mathrm{M}$ vs E curves do coincide very well in agreement with the expectation. Here the charge density has been measured directly using a new type of electrode, described in the next Section.

\section{THE DROPPING MERCURY MICRO ELECTRODE (DM $\mu$ E)}

It was discovered accidentally in our laboratory that when a high voltage (ca. $100 \mathrm{~V}$ ) was applied to a normal DME, its orifice was damaged due to excessive heating. Thereafter the drops fell off very quickly. On closer inspection we observed that this basically was caused by the shape of the orifice being elleptical instead of circular. Indeed, after cutting a "normal" capillary under a sharp angle, the same effect was accomplished [15]. Typical drop times of 3-10 ms, and corresponding drop radii of 30$60 \mu \mathrm{m}$ can be realized. The result is an electrode with an extreme large surface production per unit of time, and consequently a high charging current $I_{c}$. With a sufficiently damped device the mean charging 
current $\bar{I}_{c}$ will be measured, which will be related to the charge density according to

$$
\overline{\mathrm{I}}_{\mathrm{c}}=0.0085 \overline{\mathrm{m}}^{2 / 3} \tau^{-1 / 3} \sigma^{\mathrm{M}}
$$

where $\bar{m}$ is the mean flow rate of the mercury and $\tau$ the drop time.

At a normal DME, $\bar{m}$ will be independent of the potential, and $\tau$ a parabolic function of $E$, as it is proportional to the interfacial tension. In the case of DM $\mu E$ both $\bar{m}$ and $\tau$ were found to depend only slightly on $\mathrm{E}$, in a quite different way, as is shown in Figs. 2a and 2b. Most remarkably, the product $\bar{m} 2 / 3 \tau^{-1 / 3}$ is strictly independent of the potential, see Fig. $2 \mathrm{c}$.
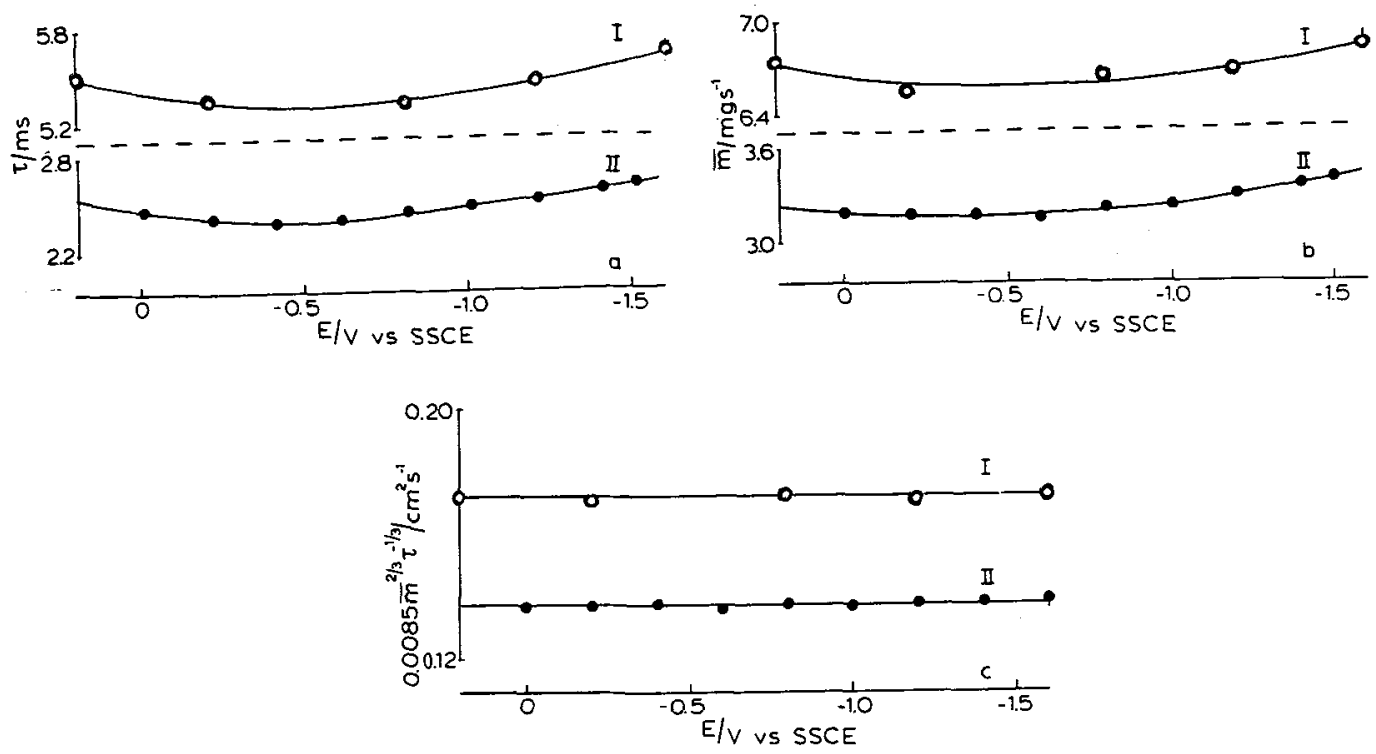

Fig.2. The potential dependence of: (a) the drop time $\tau$, (b) the mean flow rate $\bar{m} \quad$ (c) the mean surface area production of two DM $\mu$ E's: $(\bullet)$ an "exploded" capillary, (o) an obliquely cut capillary.

We have no explanation for these unusual properties, but they clearly must be related to the hydrodynamic forces acting upon the mercury flowing through the capillary. Fig. 3 gives a picture of a capillary and the falling drops, made by illuminating it with a stroboscope triggered on the current spikes at the single drops. Clearly there is a horizontal component in the velocity of the drops.

The fact that the mean surface area production is independent of the potential (Fig. 2c) is particularly useful for the application of eqn (5) in the determination of $\tau^{\mathrm{M}}$ vs E. An example is treated in the next Section. 


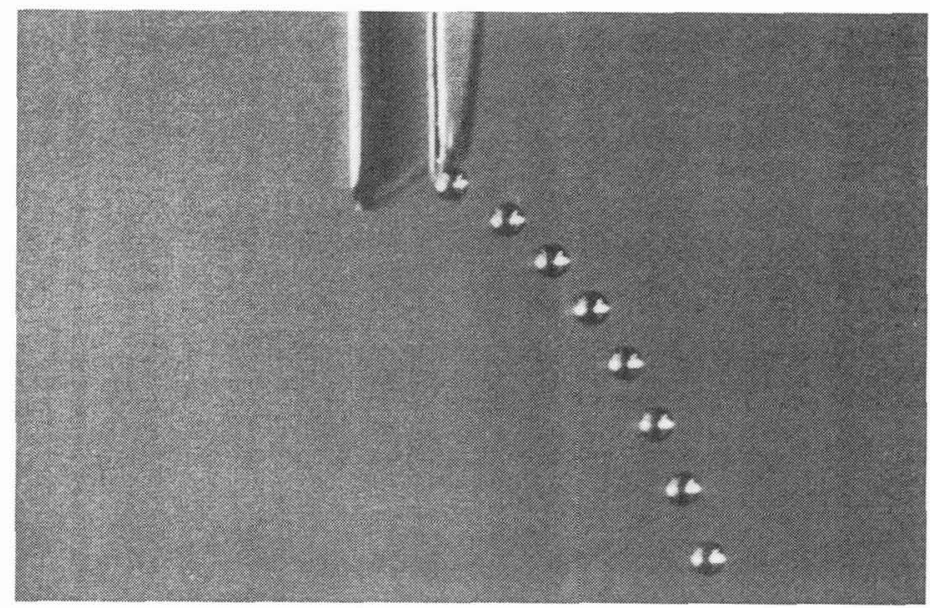

Fig. 3 Picture of a DM $\mu \mathrm{E}$ (exploded capillary). Drop radius: $53 \mu \mathrm{m}$; drop time: $2.3 \mathrm{~ms}$.

\section{SPECIFIC ADSORPTION OF ALKALI IONS AT MERCURY}

It is common practice [11] to divide the surface excess of ions into a "specially adsorbed" and a "nonspecifically adsorbed" part:

$$
\Gamma_{i}=\Gamma_{i}^{1}+\Gamma_{i}^{2-s}
$$

The latter contribution, $\Gamma^{2-s}$, due to electrostatic forces acting on the ion, is most easily computed by means of the Gouy-Chapman-Stern (GCS) theory, although this theory relies on a number of nonrigorous assumptions. Naturally the specific part, $\Gamma_{\mathbf{i}}{ }^{1}$, is of more interest, because it reflects the (competitive) interactions of ion-metal, ion-solvent, and ion-ion, etc.

Both in double-layer and charge transfer kinetics studies it is usually (silently) supposed that the alkali ions adsorb only non-specifically, in contrast with e.g. the halide anions. However, there are some indications that this might not be true:

(i) At negative potentials the double layer capacitance increases slightly with the trend $\mathrm{Li}<\mathrm{Na}<\mathrm{K}<$ $\mathrm{Rb}<\mathrm{Cs}[16]$.

(ii) Catalytic effects on the reduction of some anions increase with the same trend [17, 18].

(iii) Studies dedicated to $\mathrm{Cs}^{+}$give evidence for its specific adsorption [19].

During some experiments designed to test the $\mathrm{DM} \mu \mathrm{E}$ we observed anomalies at negative charge densities, with respect to the predictions from the GCS theory. Therefore a systematic study was set out 
to measure $\sigma^{M}$ vs $E$ in mixtures of $x \mathrm{MMCl}+(1-\mathrm{x}) \mathrm{M} \mathrm{LiCl}$, where $\mathrm{M}=\mathrm{Na}, \mathrm{K}, \mathrm{Rb}, \mathrm{Cs}$. Assuming that $\mathrm{Li}^{+}$is not specifically adsorbed, it follows from eqns (2) and (6) that

$$
\frac{1}{\mathrm{RT}} \int \frac{\partial \mathrm{E}_{-}}{\partial \ln \mathrm{x}} \mathrm{d} \sigma^{\mathrm{M}}=\Gamma_{\mathrm{M}}-\frac{\mathrm{x}}{1-\mathrm{x}} \Gamma_{\mathrm{Li}}=\Gamma_{\mathrm{M}}^{1}
$$

The evaluation of $\Gamma_{M}^{1}$ in this way needs careful data analysis and corrections, e.g. for changes in the activity coefficients and liquid junction potentials [20].

The results give quite convincing evidence for the existence of specific alkali ion adsorption. As an example the following Table lists some data for $\mathrm{x}=0.5$ :

\begin{tabular}{|l|l|l|l|l|}
\hline $\begin{array}{l}\sigma^{M} \\
\left(\mu \mathrm{Cm}^{-2}\right)\end{array}$ & $\begin{array}{l}F \Gamma_{\mathrm{Na}}^{1} \\
\left(\mu \mathrm{cm}^{-2}\right)\end{array}$ & $\begin{array}{l}F \Gamma_{\mathrm{K}}^{1} \\
\left(\mu \mathrm{Cm}^{-2}\right)\end{array}$ & $\begin{array}{l}F \Gamma_{\mathrm{Rb}}^{1} \\
\left(\mu \mathrm{C} \mathrm{cm}{ }^{-2}\right)\end{array}$ & $\begin{array}{l}F \Gamma_{\mathrm{Cs}}^{1} \\
\left(\mu \mathrm{Cm}^{-2}\right)\end{array}$ \\
\hline-10 & $\sim 0$ & 0.2 & 0.7 & 1.0 \\
\hline-15 & 0.5 & 1.2 & 2.8 & 4.3 \\
\hline-20 & 2.0 & 3.5 & 6.8 & 9.3 \\
\hline-25 & 4.9 & 7.0 & 11.0 & 14.9 \\
\hline
\end{tabular}

\section{ADSORPTION OF ELECTROACTIVE SPECIES}

Effects due to adsorption show up very sensitively in the faradaic potential region if the adsorbing species is also involved as reactant or product in a charge transfer process. In dc polarography they lead to shifts of the half-wave potential and/or to pre- and postwaves [21]. Much more sensitive are the effects on the interfacial admittance [3]. However, the mathematical description in the general case of a finite rate of charge transfer $[22,23]$ is too complex to be suitable for data analysis: the more or less implicit expressions for $Y(i \omega)$ contain 9 independent parameters to be adjusted. Only if the charge transfer rate is infinite (the "ac-reversible case") they reduce to transparent expressions containing 4 independent parameters [3]:

$$
Y(i \omega)=\frac{\omega^{1 / 2}}{2 \sigma}(1+i)+\omega C_{a} \frac{u+i(u+2)}{u^{2}+2 u+2}+i \omega C_{H F}
$$

Here $\sigma$ is the Warburg coefficient, and the meaning of $C_{a}$, $u$ and $C_{H F}$ is similar to that of the same symbols in eqns (4), however with a more complex potential dependence [for details see e.g. ref 5].

For a reaction with a finite rate of charge transfer, but with no (significant) reactant or product adsorption, the admittance is given by the well known expressions 


$$
\begin{aligned}
& Y(i \omega)=\frac{\omega^{1 / 2}}{2 \sigma} \frac{p+1+i}{p^{2}+2 p+2}+i \omega C_{d} \\
& p=p^{\prime} \omega^{1 / 2}=\left(R_{c t} / \sigma\right) \omega^{1 / 2}
\end{aligned}
$$

where $R_{c t}$ is the charge transfer resistance which contains the information on the reduction rate constant $\mathrm{k}_{\mathrm{f}}(\mathrm{E})$ and the transfer coefficient $\alpha=(\mathrm{RT} / \mathrm{nF}) \mathrm{d} \ln \mathrm{k}_{\mathrm{f}} / \mathrm{dE}$.

In our laboratory several systems were investigated assuming the validity of eqn (8). Although within the experimental accuracy the fits are usually not bad, internal inconsistency of the parameter values sometimes prompts to surmise that the reaction is not really ac reversible. Therefore we intended to try as a probably acceptable approximation in the case of weak reactant adsorption and fast charge transfer the validity of a combination of eqns (8) and (9):

$$
Y(i \omega)=\frac{\omega^{1 / 2}}{2 \sigma}=\frac{p+1+i}{p^{2}+2 p+2}+\omega C_{a} \frac{u+i(u+2)}{u^{2}+2 u+2}+i \omega C_{H F}
$$

In Fig. $4 \mathrm{a}$ the frequency dependence is illustrated of the real component of eqns (8), (9) and (10). It is immediately clear that in the latter the effects due to the reactant adsorption and the charge transfer process obscure each other, resulting in a behaviour much alike that of the Warburg admittance. The corresponding capacitance values are hardly frequency dependent and thus provide no more decisive information (Fig. 4b).
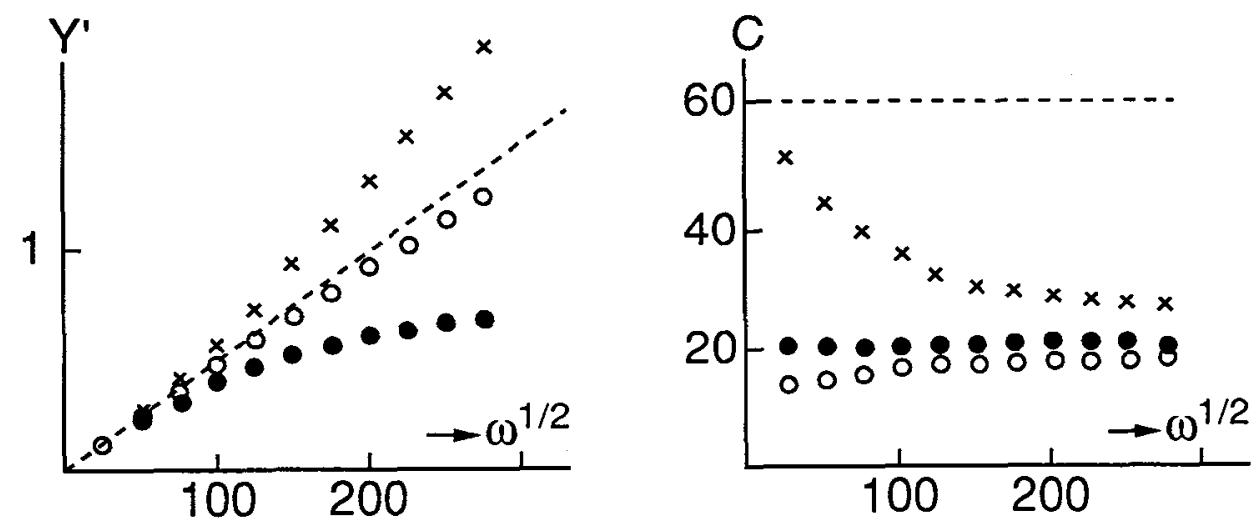

Fig. 4 The frequency dependence of (a) $Y^{\prime}$ and (b) " $C_{d} "=\left[Y^{\prime \prime}-Y^{\prime} /(p+1)\right] \omega^{-1}$, calculated from eqn (10) with:
(x) $\mathrm{u}^{\prime}=0.01 \mathrm{~s}^{1 / 2}, \mathrm{p}^{\prime}=0$;
(•) $\mathrm{u}^{\prime}=0, \quad \mathrm{p}^{\prime}=0.01 \mathrm{~s}^{1 / 2}$
(o) $\mathrm{u}^{\prime}=0.01 \mathrm{~s}^{1 / 2}, \quad \mathrm{p}^{\prime}=0.01 \mathrm{~s}^{1 / 2}$. In all cases $\sigma=100 \Omega \mathrm{cm}^{2} \mathrm{~s}^{-1 / 2}, C_{\mathrm{a}}=40 \mu \mathrm{F} \mathrm{cm} \mathrm{cm}^{-2}, C_{\mathrm{HF}}=20 \mu \mathrm{F} \mathrm{cm}^{-2}$. 
A complementary method, in this case covering a higher frequency range, is needed to unravel the effects due to the charge transfer and the reactant adsorption.

\section{THE DEMODULATION METHOD}

Basically in this method a sinusoidal current of high frequency (typically $100 \mathrm{kHz}$ ) is forced through the interface, but the voltage response is measured at a low frequency. This is achieved by modulating the current amplitude with a low frequency signal. So the perturbation signal is of the form $j=j_{A} \sin \omega_{H} t$ $\cos \omega_{\mathbf{L}} \mathrm{t}$.

Due to their non-linear character, the interfacial processes generate together a second order voltage response at the frequency $2 \omega_{\mathrm{L}}$, the demodulation voltage

$$
\Delta E_{\text {dem }}=I_{L F} \cos 2 \omega_{L} t+Q_{L F} \sin 2 \omega_{L} t
$$

The general expressions for the components $I_{L F}$ and QIF are rather complex. However, they can be combined with the components $\mathrm{Y}_{\mathrm{L}}^{\prime}$ and $\mathrm{Y}_{\mathrm{L}}^{\prime \prime}$ of the interfacial admittance measured at the frequency $2 \omega_{\mathrm{L}}$, in the useful relationship [10].

$$
I_{L F}-Q_{L F} \frac{Y_{L}^{\prime \prime}}{Y_{L}^{\prime}}=\left[S_{F}\right]
$$

in which $\left[\mathrm{S}_{\mathrm{F}}\right]$ is the demodulation response solely generated by the faradaic process. Its normalized value, $S_{F}{ }^{*}=\left[S_{F}\right](R T / n F)\left(2 / j_{A}\right)^{2}\left|Y_{H}\right|^{2}$, can readily be analyzed as a function of the electrode potential to give the kinetic parameters $\mathrm{k}_{\mathrm{f}}(\mathrm{E})$ and $\alpha(\mathrm{E})$.

Eqn (12) holds if in eqn (10) the term in $\omega C_{a}$ is almost purely capacitive, i.e. if $u=u^{\prime}\left(2 \omega_{L}\right)^{1 / 2}$ is sufficiently small [24]. In that case the demodulation method provides the way to obtain the kinetic parameters in the high frequency domain, which thereafter can be used to calulate $R_{c t}$ as a funtion of $E$, to be inserted into eqn (10).

An example of the application of this principle is discussed in the following Section.

\section{THE REDOX SYSTEM Tl (I) / Tl Hg) IN $1 \mathrm{M} \mathrm{HClO}_{4}$}

The specific adsorption of $\mathrm{Tl}(\mathrm{I})$ is known to occur since long [25]. It is sufficiently weak to fulfil the conditions set in the previous Section. 
In Fig. 5 we compare the values of the adsorption capacitance $C_{a}$ obtained a) using eqn (8) and $b$ ) using eqn (10). To calculate $p^{\prime}$ in the latter, the data on $k_{f}(E)$ and $\alpha(E)$, derived from the demodulation voltage $\left[\mathrm{S}_{\mathrm{F}}\right]$ were used. Fig. 6 shows $\mathrm{S}_{\mathrm{F}}{ }^{*}$ as a function of $\mathrm{E}_{\text {. }}$

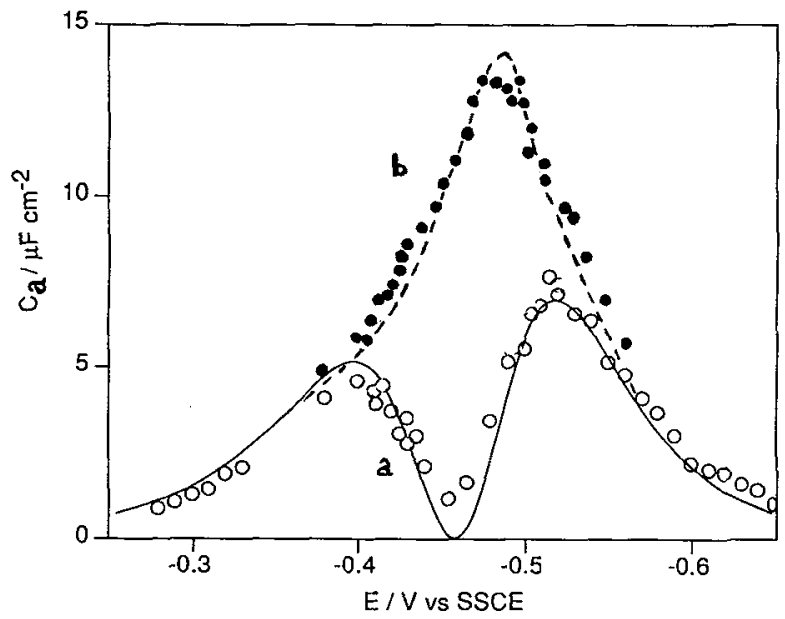

Fig. 5 The adsorption capacitance in the faradaic potential region of the $T 1$ (I) reduction, from admittance data analyzed with: (a) eqn (8) and (b) eqn (10), for $5 \mathrm{~m} \mathrm{MTl}$ (I).

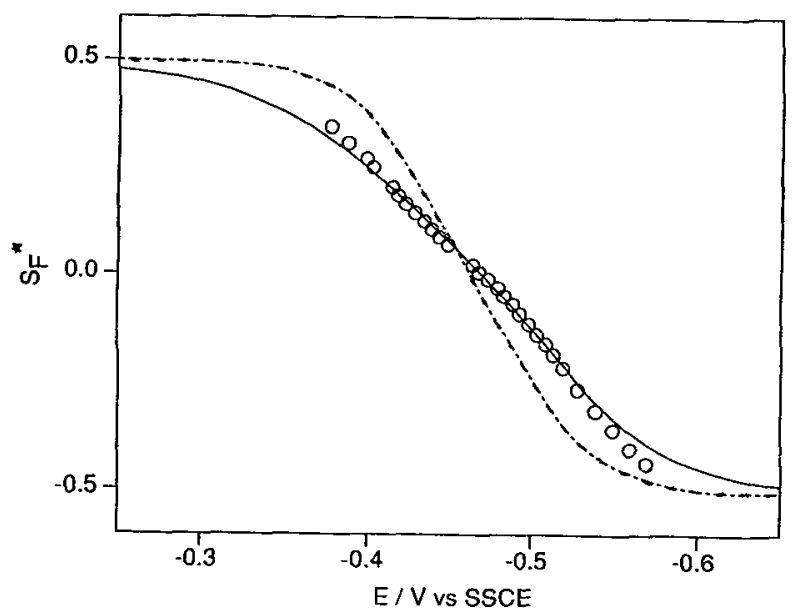

Fig. 6. The faradaic demodulation voltage as a function of the electrode potential. Points: experimental; $(-)$ theoretical; (....) theoretical for infinitely fast charge transfer. 
The rate constant $k_{f}(E)$ obeys the relationship $k_{f}(E)=k_{s} \exp \left[\alpha(F / R T)\left(E-E^{0}\right)\right]$ with $k_{s}=1.2 \pm 0.03$ $\mathrm{cm} \mathrm{s}^{-1}$ and $\alpha=0.57 \pm 0.01$. Its effect on the admittance analysis is rather dramatic. This is the first time that the kinetic parameters of a charge transfer reaction were determined taking into account the influence of the adsorption of the reactant.

\section{REFERENCES}

1. D.E. Smith in (A.J. Bard, Ed.) Electroanalytical Chemistry, Dekker, N.Y., Vol. 1 (1966) p.1

2. D.E. Smith, Crit. Rev. Anal. Chem. 2 (1971) 247

3. M. Sluyters-Rehbach and J.H. Sluyters in (A.J. Bard, Ed.) Electroanalytical Chemistry, Dekker, N.Y., Vol. 4 (1970) p. 1

4. S.K. Rangarajan, J. Electroanal. Chem. $\underline{55}$ (1974), 297, 329, 337, 363

5. M. Sluyters-Rehbach and J.H. Sluyters in (C.H. Bamford and R.G. Compton, Eds.) Chemical Kinetics, Elsevier, Vol. 26 (1986) 203

6. J.R. MacDonald (Ed.), Impedance Spectroscopy, Wiley, N.Y. (1987)

7. R. de Levie in (P. Delahay and C.W. Tobias, Eds.) Adv. Electrochem. Electrochem. Eng., Wiley, N.Y., Vol. 6 (1967) 329

8. T. Pajkossy and L. Nyikos, Phys. Rev. B42 (1990) 709

9. W.H. Reinmuth, J. Electroanal. Chem. 34 (1972) 297

10. J. Struijs, M. Sluyters-Rehbach and J.H.Sluyters, J. Electroanal. Chem. 146 (1983) 263; 171 (1984) 157,177

11. D.M. Mohilner, in (A.J. Bard, Ed.) Electroanalytical Chemistry, Dekker, N.Y. Vol. 1 (1966) Ch. 4

12. F.C. Anson, R. Marin and Ch. Yarnitzy, J. Phys. Chem. 73 (1969) 1835

13. K. Doblhofer and D.M. Mohilner, J. Phys. Chem. 75 (1971) 1689, and references cited therein

14. A. de Battisti, B.A. Abd-El-Nabey and S. Trasatti, J. Chem. Soc. 72 (1976) 2067

15. A. Baars, M. Sluyters-Rehbach and J.H. Sluyters, J. Electroanal. Chem. 283 (1990) 99

16. D.C. Grahame, J. Electrochem. Soc. $9 \underline{9}$ (1951) 343

17. A.N. Frumkin, Z. Elektrochem. $\underline{59}$ (1955) 807

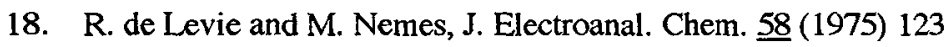

19. B.B. Damaskin, J. Electroanal. Chem. 65 (1975) 799, and references cited therein

20. A. Baars, M. Sluyters-Rehbach and J.H. Sluyters, J. Electroanal .Chem. 329 (1992) 171

21. J. Heyrovsky and J. Kuta, Principles of Polarography, Acad. Press, N.Y. 1966

22. M. Moreira and R. de Levie, J. Electroanal. Chem. 25 (1972) 103

23. R.L. Birke, J. Electroanal. Chem. 33 (1971) 201

24. S.G.J. Blankenborg, M. Sluyters-Rehbach and J.H. Sluyters, J. Electroanal. Chem., in press.

25. A.N. Frumkin and A. Titievskaja, Zh. Fiz. Khim. $\underline{31}$ (1957) 485 